\title{
Uma abordagem da circulação do sujeito pelo universo da escrita via mecanismos de junção
}

\author{
Lúcia Regiane Lopes-Damasio \\ Universidade Estadual Paulista "Júlio de Mesquita Filho" (UNESP), Assis, São Paulo, Brasil \\ luregiane@assis.unesp.br
}

DOI: http://dx.doi.org/10.21165/el.v46i3.1757

\begin{abstract}
Resumo
Neste trabalho, busca-se um ponto de observação da argumentação, em textos produzidos por sujeitos do primeiro ano do Ensino Fundamental público de Assis (SP), em fase de aquisição do modo escrito de enunciar. Propõem-se relações entre o conceito de Tradição Discursiva, baseado no pressuposto de que os textos têm história e de que essa história pode determinar os usos textuais, independentemente de seus modos de enunciação, e os elementos juntivos do texto, considerados em/como espaços de repetibilidade que mostram os diferentes tipos de circulação do escrevente pelo que imagina ser a escrita. Os resultados revelaram que o emprego dos MJ com destaque para os com acepção causal e condicional - reflete a constituição de uma tradição, em que o efeito argumentativo é produzido em meio à incompletude e à heterogeneidade que são constitutivas da linguagem/língua, intimamente ligado aos encadeamentos discursivos marcados na cadeia sintagmática, ainda que prioritariamente por zero.
\end{abstract}

Palavras-chave: escrita; mecanismos de junção; tradição discursiva; argumentação.

An approach to the circulation of the subject in the universe of writing through the mechanisms of junction

\begin{abstract}
In this paperwork, a point of observation on the argumentation is searched in texts that were produced by subjects of the first year of Elementary School in the public teaching system of the city of Assis (SP), during the phase of acquisition of the written manners of enunciating. Relations were searched between the concept of Discursive Tradition, based on the presupposition that texts have some history and that this history may determine textual uses, regardless of their ways of enunciating, and the conjunctive elements of the text, considered in/as spaces of repetition that show all different types of circulation of the writer through what they imagine what writing is. The results revealed that the usage of the Junction Mechanisms (MJ) - with emphasis on the ones with causal and conditional meanings - reflect the constitution of a tradition, in which the argumentative effect is produced amid the incompleteness and the heterogeneity that are part of the speech/language and which are intimately connected to the discursive series attached to the syntagmatic chain, even though primarily by zero.
\end{abstract}

Keywords: writing; mechanisms of junction; discursive tradition; argumentation.

\section{Apresentação}

Neste trabalho, busca-se um ponto próprio de observação da argumentação, em textos produzidos por sujeitos em fase de aquisição do modo escrito de enunciar, por meio da análise dos mecanismos de junção (MJ) do texto, considerados em/como espaços de 
repetibilidade, que mostram os diferentes tipos de circulação do escrevente pela escrita (cf. CORRÊA, 2004).

A partir da pergunta: quais os aspectos sintomáticos da junção na/para a delimitação de uma tradição discursiva (TD) argumentativa, em aquisição da escrita (AE)?, persegue-se a hipótese de que o efeito argumentativo é produzido em meio à heterogeneidade constitutiva da linguagem/língua e de que está intimamente ligado aos encadeamentos discursivos marcados na cadeia sintagmática. Nessa direção, fundamentase a investigação no cruzamento de três lugares teóricos distintos, mas que aqui se complementam: (i) uma base teórica que entende a escrita como constitutivamente heterogênea e como modo de enunciação (CORRÊA, 2004); (ii) uma concepção de aquisição dessa escrita que considera as tradições de falar/escrever (ABAURRE et al., 2002; KABATEK, 2005); e (iii) um modelo funcionalista de junção fundado na não discretude dos processos e num arranjo bidimensional (RAIBLE, 2001). Por sua vez, a argumentação é tomada como tradição, entendida a partir de um afastamento da retórica e de uma aproximação da língua e da ilusão argumentativa (CAMPOS, 2005; PEREIRA DE CASTRO, 1996).

O universo de investigação compõe-se de 186 textos, produzidos por sujeitoscrianças, em aquisição do modo escrito de enunciar, regularmente matriculados no $1^{\circ}$ ano do Ensino Fundamental (EF) público do município de Assis-SP. Os textos foram coletados, em 2015, a partir da aplicação de dez propostas de produção textual a uma média de 24 alunos, com recursos do Programa Primeiros Projetos (PROPe/UNESP).

Para a realização da análise, foram conjugadas as abordagens quantitativa e qualitativa, mediante as frequências token e type (BYBEE, 2003), com o mapeamento dos MJ dos textos. Alguns aspectos metodológicos devem ser considerados, neste momento, a fim de esclarecer posicionamentos oriundos das diferentes orientações teóricas que, conjugadas, permitem alcançar o objetivo deste trabalho:

(i) a adoção do paradigma das TD prevê, antes de qualquer coisa, uma entrada na investigação dessas tradições por meio de aspectos linguísticos que lhes são considerados sintomáticos, ou seja, que apontam para a caracterização de uma dada tradição de falar/escrever. Tais aspectos, na trilha dos trabalhos de Kabatek (2005) - que idealizou essa hipótese de correlação -, são os MJ;

(ii) a análise direcionada por um olhar voltado a esses mecanismos exigiu, no entanto, uma metodologia particular que se funda, de forma coerente, numa proposta funcionalista de abordagem da junção, que, concomitantemente, cruza os eixos tático e semântico e aceita a fluidez como característica fundamental de qualquer funcionamento que se deixe ver a partir do prisma da língua concreta, em uso; e

(iii) para delinear essa relação, tornou-se imprescindível a adoção do paradigma indiciário, eminentemente de cunho qualitativo, conforme Ginsburg, para a investigação da relação sujeito/linguagem, e, ao mesmo tempo, a adoção de um paradigma inspirado no modelo galileano, naquilo que tem de centrado na quantificação e na repetibilidade.

A particularidade dos textos analisados deve-se, além do fato de configurarem um retrato da $\mathrm{AE}$, também ao fato de que configuram um retrato marcado pelas características da TD argumentativa, tão pouco comum em textos produzidos no primeiro ano do EF. 
Em outras palavras, o trabalho focalizou os textos coletados em que a orientação argumentativa, tratada como uma questão linguística e não lógica, psicológica e nem sociológica, configura o que será denominado, na trilha de Pereira de Castro (1996) e Campos (2005), com inspiração na proposta ducrotiana, de ilusão argumentativa. É nesse universo que se procura encontrar a correlação entre TD e junção, sem deixar escapar as relações entre a $\mathrm{AE}$ e o diálogo que se trava entre essas relações e o que é tradição, no âmbito do oral/letrado e do falado/escrito.

\section{Fundamentação teórica}

\subsection{O olhar via tradições discursivas}

O conceito de TD, mobilizável na construção e recepção do sentido via discurso, apresenta características textuais e pragmáticas por corresponder a modelos textuais, convencionalizados social e historicamente, que integram a memória de sujeitos enquanto membros de comunidades. Essa noção surge nos estudos da Linguística Histórica Românica, realizados pela Filologia Pragmática alemã, na década de 80 . O termo Diskurstradition, proposto por Koch e adotado por outros linguistas alemães, como Oesterreicher e Kabatek, objetiva dar "uma expressão conceitual à fundamentação histórica dos gêneros textuais" (ASCHENBERG, 2002, p. 157 apud ZAVAM, 2009, p. 66) e fundamenta-se em concepções teóricas de Coseriu sobre a linguagem humana. Para resgatá-las e tornar compreensível o caminho que leva ao conceito de TD, recuperase o diálogo com o pensamento aristotélico de Humboldt, dado que a teoria da linguagem coseriana apoia-se na ideia de que a linguagem não é produto, mas atividade. Segundo Coseriu (1982), enquanto atividade criadora, a linguagem não é "acabada", "coisa feita", "produto estático", mas um conjunto de "modos de fazer", um sistema de produção que surge, apenas em partes, como produtos materializados linguisticamente, reconhecíveis como textos falados e escritos.

Para a construção desse conceito, adota-se a concepção coseriana de linguagem e de língua - historicista e oposta à doutrina saussuriana. Para Coseriu (1979), a língua é concreta e histórica, mesmo se abordada num recorte sincrônico. Em sua teoria da linguagem, o autor propõe três níveis do linguístico: (i) o universal, em que a linguagem é considerada como atividade do falar, enquanto fato antropológico, sem distinção histórica, representando aspectos universais genericamente humanos; (ii) o histórico, em que é considerada como língua particular - o espanhol, o português etc., incluindo suas variedades; e (iii) o atual ou individual, em que é considerada como "ato linguístico [...] de um indivíduo determinado numa situação determinada" (COSERIU, 1981, p. 272 apud $\mathrm{KOCH}, 2008$, p. 53). Os três níveis estão presentes sempre que o sujeito enuncia: falar/escrever significa, ao mesmo tempo, recorrer ao que tradicionalmente está instituído, do ponto de vista do idioma e das sucessivas atualizações de uma forma discursiva, e colaborar para a constituição dessa tradição, num diálogo complexo entre o já-dito e os novos projetos de dizer.

Segundo Koch (2008), independentemente da língua (com suas especificidades estruturais, gramaticais e lexicais), existem tradições textuais, nas quais a configuração que uma determinada intenção comunicativa assume pode independer da tradição linguística naquela língua e fixar-se, assim, em tradições do discurso. Com base nessas considerações, o autor propõe a bipartição do nível histórico, acrescentando à história da 
língua a história das TDs e considerando que a segunda perpassa, transversalmente, a primeira. Assim, a partir de uma intenção, o ato comunicativo é filtrado pela organização linguística, na qual os signos são escolhidos, seguindo as regras sintáticas e a norma de uma língua ou variedade de língua particular, e, concomitantemente, pela ordem textual, responsável pela atualização de determinada $\mathrm{TD}^{1}$.

As TDs estão associadas, portanto, ao fato de um sujeito, diante de uma finalidade comunicativa, produzir seu discurso em conformidade com o já-dito, na sociedade em que está inserido como sujeito. Sob essa base conceitual, Oesterreicher (1997) define TDs como moldes normativos, convencionalizados, que guiam a transmissão de um sentido mediante elementos linguísticos em sua produção e recepção. $\mathrm{O}$ termo tradição discursiva abarca, segundo Kabatek (2005), uma ampla gama de fenômenos. Por essa razão, o autor propõe uma definição que enfatiza essa amplitude conceitual e inclui todo tipo identificável de tradição de falar/escrever.

Nem toda repetição linguística formará uma TD. É necessária uma combinação particular de uma série de elementos para tornar possível a inserção de um texto nessa categoria: uma combinação de elementos, uma vez evocada, em uma situação concreta de interação verbal, produzirá efetivamente uma repetição e sua concretização produzirá significado. Essa combinação aponta, ainda, para a composicionalidade das TDs, que pode ser: (i) paradigmática, dado que o texto pode agregar um conjunto de tradições, não necessariamente pertencentes a uma mesma área do saber; e (ii) sintagmática, que, num âmbito local, refere-se aos arranjos linguísticos realizados nas combinações que se dão na linearidade da linguagem, a partir de escolhas paradigmáticas.

Kabatek (2004) afirma que uma TD pode se formar a partir de qualquer elemento significável, formal ou de conteúdo, cuja re-evocação estabelece um laço entre atualização e tradições, isto é, qualquer relação semiótica entre enunciados, seja a partir do ato mesmo de enunciação, seja a partir dos elementos referenciais, de certas características da forma textual ou dos elementos linguísticos empregados. As TDs implicam, então, a relação de um texto com outro em determinado momento histórico, via repetição, total, parcial, ou marcada apenas pela repetição formal. Segundo Kabatek (2005), considerar as TDs textualmente abrange apenas um dos seus aspectos (o que mais se destaca, neste trabalho). No entanto, a explicação desse aspecto depende da contraparte que o evoca. Assim, o autor propõe duas fases: a TD propriamente dita e a constelação discursiva evocada por ela. Nessa perspectiva, a TD adquire valor de signo, reconhecido por meio de outros signos que extrapolam os limites textuais. A respeito dessa relação, o autor destaca o diálogo intrínseco entre TD, o já-dito, o que se diz e o(s) projeto(s) de dizer, sem, com isso, reduzir a novidade de cada acontecimento discursivo.

\footnotetext{
${ }^{1}$ Koch $(2008$, p. 55) lembra que os grupos constitutivos das TDs são profissionais, religiosos, correntes literárias, movimentos políticos etc., enquanto os constitutivos das línguas históricas são comunidades linguísticas. Dessa forma, as línguas históricas - incluindo aí suas variedades - definem os grupos (as comunidades linguísticas), enquanto os grupos (profissionais, religiosos, literários etc.) definem as TDs.
} 


\subsection{O olhar via aquisição da escrita}

A criança domina várias TDs antes de inserir-se no modo escrito de enunciação, especialmente aquelas que se constituem no campo da fala/oralidade. É esperado, pois, que o modo de enunciar que ela domina constitua as práticas mais recentes associadas ao modo que está adquirindo (o escrito). Nas operações iniciais da escrita infantil, no início da circulação da criança por esse novo universo, conforme Abaurre et al. (2002, p. 1617), o que normalmente é entendido como erro - a partir de um olhar pautado no modelo de gramática do adulto -, corresponde a indícios de um processo, em curso, de representação escrita da linguagem. Esses "erros" ganham estatuto, portanto, de registro dos momentos em que a criança evidencia a sua manipulação da linguagem, (re)construindo essa relação por meio de sua inserção em práticas de escrita e leitura.

Segundo Abaurre et al. (2002), a AE é um momento particular de um processo mais geral de aquisição da linguagem, no qual, ao reconstruir, a todo momento, sua relação com a linguagem, o sujeito toma diferentes caminhos para diferenciar e relacionar as manifestações orais/faladas e letradas/escritas de uma mesma língua. Desse ponto de vista, a posição de sujeito seria também, essencialmente, histórica, regulada pela linguagem - historicamente constituída - e pela atuação do outro, que o interpela, o afeta e é afetado por esse processo. O outro deve ser considerado em sua dimensão física e empírica, bem como enquanto instância de representação do funcionamento convencional da linguagem, em seu modo escrito de enunciação, a partir de representações que o sujeito escrevente faz sobre ele. Para Abaurre et al. (2002), o lugar desse processo é a interlocução entre sujeitos que se constituem em outros para seus interlocutores, constituindo-os também como sujeitos.

No diálogo travado entre a criança e o adulto letrado, encontram-se indícios, segundo Abaurre et al. (2002), de que ambos os sujeitos se movimentam, já que o que o adulto faz e diz repercute no que a criança faz e diz e vice-versa. $\mathrm{O}$ adulto letrado constitui-se num outro para o sujeito-criança, e confronta-o com a ideia de que a escrita veicula sentidos e não é simples sequência de letras desenhadas ao acaso, o que desencadeia, nesse sujeito, a busca por esses sentidos. Por outro lado, a criança, constituindo-se num outro para o sujeito-adulto letrado, confronta-o com sua leitura "sem sentido", na qual o sujeito-adulto busca com sua própria visão de letrado, na escrita, exigências que só fazem sentido para quem já lê e já escreve há muito tempo. A criança, ao não utilizar as convenções (pré-)estabelecidas pelo sistema, força o adulto a rever sua leitura e a aceitar o que é oferecido por ela como um sentido (dentre outros).

O sujeito é considerado a partir de sua individualidade e entendido, dessa forma, em sua dimensão real e na sua história individual de relação com a linguagem. Por sua vez, a linguagem é concebida como um lugar de interação, de interlocução, é tomada como atividade e, mais do que isso, como trabalho. A relação sujeito/linguagem assentada em uma noção de sujeito oposta, portanto, à psicológica - é vista como um processo não-cumulativo, com idas e vindas, reelaborações, reestruturações, variações, generalizações e, mesmo, idiossincrasias, tomadas como indícios, no sentido ginsburguiano, dos movimentos dos sujeitos em constituição. A AE, portanto, é vista como um processo complexo de contínua, porém, não linear mudança na relação sujeito/linguagem, sempre intermediado pelo outro, levando a criança a construir conhecimentos que a habilitariam a se tornar escrevente/leitor de sua língua materna. 
Capristano (2007, p. 71) afirma que, embora o sujeito-criança busque o funcionamento convencional do modo escrito da linguagem, "essa ação é regulada, controlada e organizada em função da linguagem tal como ela comparece nas práticas sócio-histórico-culturais (faladas e escritas) desempenhadas pelos sujeitos em diferentes espaços-tempos". Sendo assim, completa-se que as hipóteses do sujeito incidem sobre possibilidades abertas pelo próprio sistema da língua e pelo universo do que é tradicional naquele modo de enunciar, ou seja, pelas TDs.

\subsection{O olhar via mecanismos de junção}

Raible (2001) chama junktion à dimensão universal da linguagem que permite a sistematização das diferentes técnicas linguísticas usadas para juntar/combinar elementos proposicionais. Nessa direção, os juntores são analisados, conforme a metodologia desse autor, a partir da conjugação de dois eixos, com diferentes graus de complexidade, a saber: um sintático (vertical) e outro semântico (horizontal). No eixo sintático, parte-se dos elementos mais agregadores até os mais integradores. No horizontal, somam-se as relações semântico-cognitivas expressas pelos juntores, seguindo uma "escala cognitiva de complexidade crescente". De acordo com esse esquema, uma mesma relação semântica pode encontrar possibilidades variadas de expressão tática. Essa forma de analisar os MJ distancia-se, portanto, da tradição gramatical, em que são associadas "por exemplo, adversidade e coordenação, condição e subordinação" (LONGHINTHOMAZI, 2011, p. 230-231). A análise se fundamenta, assim, num modelo funcionalista de linguagem em que a relação entre as orações está pautada na não discretude dos processos e sentidos da junção.

Em relação ao grau de interdependência, o sistema de taxe se desdobra em parataxe e hipotaxe, que se distinguem nos aspectos gramaticais das unidades envolvidas: (i) se ambas as orações são livres e constituem, assim, cada uma, um todo funcional, a construção é paratática (ordem fixa); (ii) se, por outro lado, uma oração domina/modifica a outra, é dominante e, portanto, nuclear, enquanto a outra é dependente e, portanto, modificadora, a construção é hipotática (há dependência). Em relação ao crescente de complexidade cognitiva das relações semânticas (eixo horizontal), destaca-se sua relação com a unidirecionalidade da mudança semântica, constatada em diversos trabalhos (cf. KORTMANN, 1997; LONGHIN-THOMAZI, 2011; LOPES-DAMASIO, 2014 etc.), que aponta para uma relação de derivação entre as categorias espaciais e modais em direção a tempo e CCCC (causa, condição, contraste e concessão); e de derivação entre tempo e CCCC.

A análise das relações desempenhadas pelos juntores, de acordo com esse critério bidimensional, será usada como argumento indicativo da circulação do escrevente pelo (seu) imaginário sobre a escrita e da dialogia com o já falado-escrito, em contexto determinado sócio-historicamente. A peculiaridade desse tratamento encontra-se no fato de enxergar a prática de textualização não como produto textual - no sentido de que há um produtor de texto que se antecipa ao próprio texto, enquanto fonte/origem do dizer -, mas como um processo de textualização em que o sujeito se constitui como escrevente num texto que se constitui numa tradição. 


\section{Descrição e análise dos dados}

\subsection{Práticas orais/faladas e letradas/escritas na escrita em constituição}

O material coletado divide-se em dois grupos: o dos textos que não permitem proposta(s) de leitura, por ainda caracterizarem uma relação incipiente entre o sujeito e a escrita, cf. (1) e (2); e o dos textos que permitem ao menos uma proposta de leitura, por se encontrarem aproximados, em graus distintos, da escrita alfabética, cf. (3) e (4):

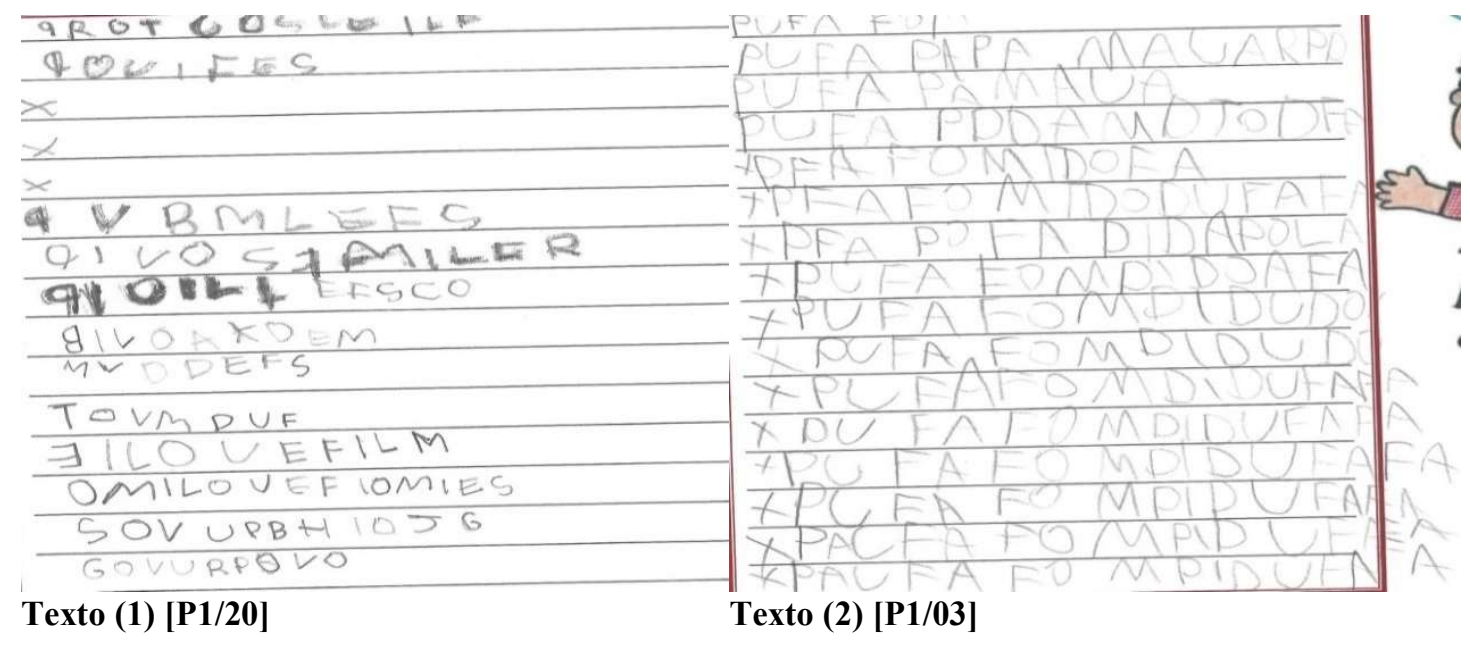

Embora, tanto em (1) quanto em (2), haja a preocupação dos sujeitos em preencher o espaço em branco da folha destinado ao texto, o que pode ser percebido por meio de recursos diferentes - marcações com " $x$ " e disposição de grupos de letras em cada linha, em (1), e preenchimento completo do espaço, em (2) - a relação de cada um dos sujeitos com o código escrito é particular. Em (1), é impossível encontrar correspondências ao conceito de palavra ou frase, nos moldes da escrita alfabética, como código institucionalizado, o que inutiliza a tentativa de proposição de uma leitura ou paráfrase para a produção. Há, no entanto, apenas a utilização de letras (ainda que algumas se encontrem espelhadas). Em (2), é possível encontrar algumas palavras e/ou frases, como, por exemplo, no trecho "PUFAFOMDIDUFAFA", lido pelo aluno, no momento da coleta, como "Por favor, mãe do Rafa". Essa sequência, no entanto, se repete no texto, com algumas alterações, de modo que não é possível atribuir, a não ser de modo muito artificial, uma proposta de leitura além desse trecho.

Os textos (3) e (4) ilustram casos a que é possível atribuir ao menos uma proposta de leitura, por se encontrarem aproximados, em graus distintos, da escrita alfabética. Nesses textos, diferentemente de (1) e (2), os sujeitos escreventes não se preocupam em preencher totalmente o espaço em branco destinado à produção, apenas com o "texto escrito". O espaço é dividido entre o texto e a ilustração, conforme orientado inicialmente, na aplicação da proposta. Há, entretanto, particularidades na forma de se relacionar com o código escrito em cada um desses exemplos. 


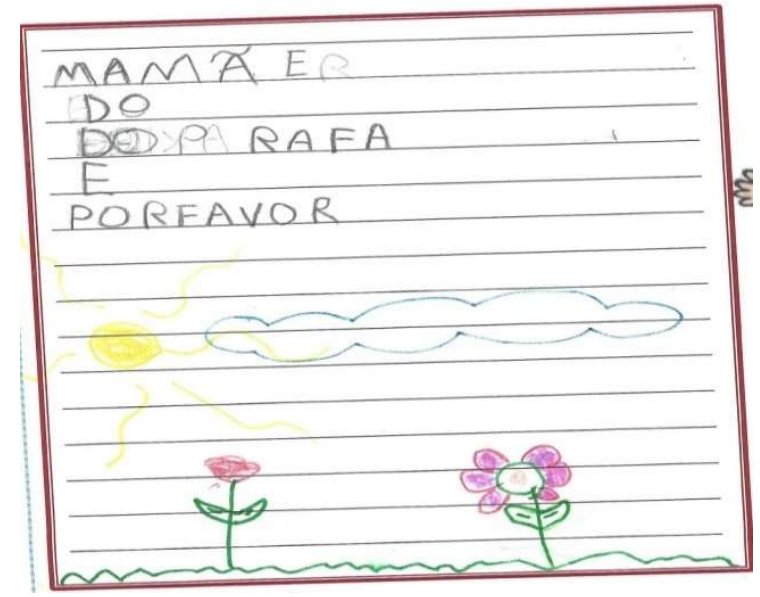

Texto (3) [P1/17]

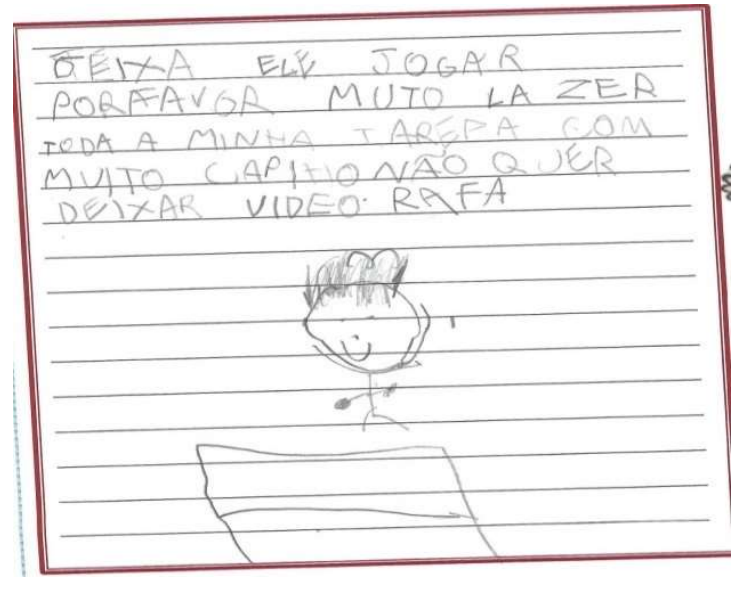

Texto (4) $[\mathrm{P} 1 / 24]$

Em (3), uma grande parte do dizer proposto no texto fica subentendida, ou seja, extrapola os encadeamentos materializados no texto, que, apesar disso, é passível de paráfrase em todos os seus segmentos, em termos de um pedido, destinado a alguém, com a intenção de persuadir e convencer, por meio desse apelo ${ }^{2}$. Nesse texto, é possível encontrar reflexos da apropriação da escrita como código institucionalizado, enquanto índice do momento em que o escrevente tende a tomá-la a partir do que imagina ser o modo autônomo de representação da oralidade (ver, por exemplo, a escrita ortográfica da palavra mamãe, e o uso, em uma linha separada, portanto, não amalgamado, do juntor $e$ ). Trata-se, em outras palavras, da escrita socialmente reconhecida e normatizada, a partir das experiências desse escrevente com a própria visão escolar sobre a escrita, em que as marcas do oral/falado seriam consideradas desvios. Dessa forma, percebe-se o cuidado de, nas poucas palavras que constituem o seu texto, o escrevente buscar correspondência com o texto da proposta. Não se trata, como entendido aqui, de uma simples "cópia", mas de um indício da circulação do sujeito pelo segundo eixo, proposto por Corrêa $(1997)^{3}$, para a observação do encontro entre esse sujeito e a escrita. O terceiro eixo desse autor também pode ser constatado aqui, uma vez que o texto é marcado pelas características de repetição e tradição que o atualizam enquanto dizer que ecoa outros dizeres via relação que o texto do escrevente mantém como o já falado/escrito e com o já ouvido/lido.

Em (4), embora haja uma explicitação maior em termos do projeto de dizer do escrevente, materializado no modo escrito de enunciar, há, além do segundo eixo, ou seja,

\footnotetext{
${ }^{2}$ Essa relação está associada ao entendimento conferido à argumentação, neste trabalho.

${ }^{3}$ Corrêa (2004) cria, metodologicamente, um lugar para a observação do encontro entre as práticas orais/faladas e letradas/escritas, construído por meio de três eixos de representação da escrita. O primeiro deles é o do modo de constituição da escrita em sua gênese e refere-se aos momentos em que o escrevente, ao apropriar-se da escrita, tende a tomá-la como representação integral da oralidade/fala, igualando/plasmando esses dois modos de realização da linguagem verbal. O segundo eixo caracteriza-se pela apropriação da escrita como código institucionalizado e refere-se aos momentos em que o escrevente tende a tomá-la a partir do que imagina ser o modo já autônomo de representar a oralidade, ou seja, tratase da escrita socialmente reconhecida e normatizada, a partir das experiências do escrevente com a própria visão escolar sobre a escrita, em que as marcas do oral/falado seriam consideradas desvios, devendo ser tomadas como algo que lhe é exterior. O terceiro eixo caracteriza-se pela relação que o texto do escrevente mantém como o já falado/escrito e com o já ouvido/lido, ou seja, com o que imagina ser a relação apropriada com a exterioridade que constitui o seu texto - outros textos, a própria língua, outros registros, outros enunciadores -, o que coloca em pauta as relações com as TDs.
} 
da preocupação em tomar a escrita como modo autônomo de representar a realidade (ver, por exemplo, os espaços em branco, separando as palavras usadas no texto), também os indícios de um sujeito que circula pelo modo escrito de enunciar, plasmando-o ao modo de representação integral da oralidade/fala (ver, por exemplo, o uso de justaposições no encadeamento dos enunciados), característicos do primeiro eixo de Corrêa (1997), sem deixar de ecoar o já falado/escrito e já ouvido/lido (terceiro eixo), que insere o texto numa tradição textual/discursiva.

Guardadas as especificidades sumariamente apresentadas, de modo geral, 136 dos textos coletados pertencem ao grupo que estamos chamando de alfabéticos ((TA) $73,11 \%$ ) e 50 ao dos não-alfabéticos ((TNA) 26,89\%), cf. as Propostas (P) aplicadas:

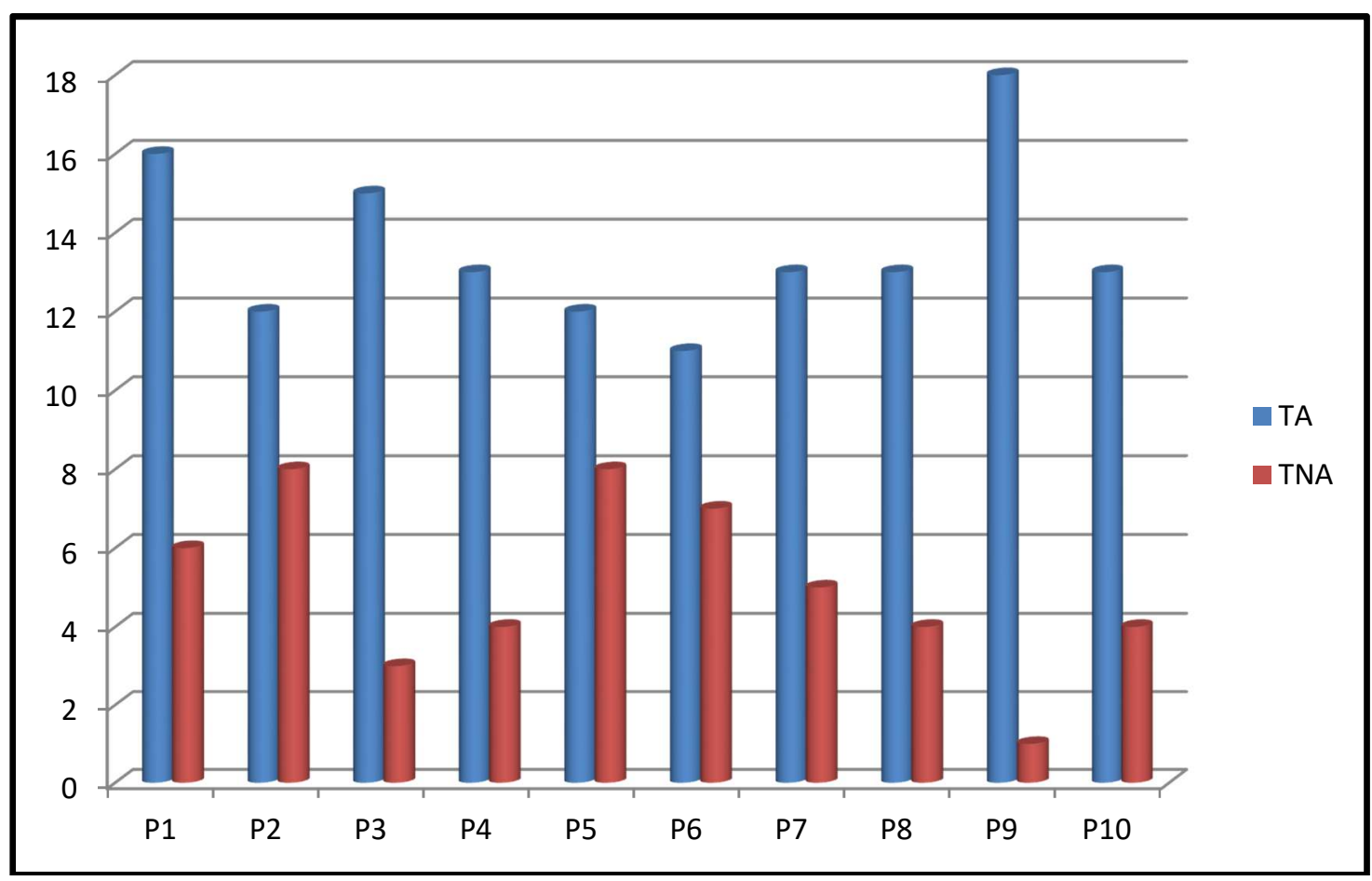

Gráfico 1. Produção de textos alfabéticos no primeiro ano do EF

Como mostra o Gráfico 1, a variação dos sujeitos pelos dois grupos mantém, no entanto, uma predominância de TA, ainda que de acordo com as especificidades apresentadas, ou seja, em que as propostas de leituras assumem amplitudes distintas a partir da própria circulação dos sujeitos pelo universo da escrita. Desde a primeira proposta, esse foi o resultado encontrado. Ainda assim, chama-se a atenção para a diminuição dos TNA, especialmente a partir da P5 até a P9, em que apenas a um texto não foi possível atribuir uma proposta de leitura (P5 - 8 ( 40\%); P6 - 7 ( 38,88\%); P7 - 5 ( 27,78\%), P8 - $4(23,53 \%)$ e P9 - $1(5,27 \%))$.

A partir desse universo, passa-se a apresentar a análise dos mecanismos de junção, voltada especialmente para a depreensão das relações táticas e semânticas empreendidas nos encadeamentos do tipo $X$ conectivo $Y$, mesmo nos casos de não explicitação do conectivo, especificamente em TA. 


\subsection{Relações tático-semânticas em TD argumentativas}

Foram identificados 174 encadeamentos do tipo $X M J Y$, predominantemente justapostos $(105-60,34 \%)$, reforçando resultados de estudos realizados na mesma perspectiva assumida aqui (cf. LOPES-DAMASIO, 2014; TUÃO-BRITO, 2014; LONGHIN-THOMAZI, 2011). Em seguida, tem-se o emprego de se, (27-15,51\%), com frequência acima da de $e(23-13,21 \%)$, resultado que se distancia de estudos anteriores porque se associa aos aspectos sintomáticos da junção em relação à TD. A partir daí, há uma variedade de $\mathrm{MJ}$, que vai do emprego do gerúndio $(5-2,87 \%)$ e da locução adverbial depois de $(3-1,72 \%)$, até os casos de $e+$ também $(2-1,14 \%), e+$ depois $(1-0,57 \%)$, depois que $(1-0,57 \%)$, passando por MJ prototípicos, como mas $(2-1,14 \%)$ e porque $(2-1,14 \%)$, além de os adverbiais e preposicionais, como depois $(1-0,57 \%)$, senão $(1$ $-0,57 \%)$ e para $(1-0,57 \%)$.

Essa descrição evidencia, na contramão das expectativas, uma variedade de expedientes - além da justaposição e do $e$ - usados na articulação dos enunciados produzidos por sujeitos que experimentam o início do processo de alfabetização, atuando na configuração dos efeitos de sentido dos/nesses textos, e uma possível relação com o letramento desses sujeitos, que circulam pelo que imaginam ser a gênese da escrita, o código escrito institucionalizado e o já-falado/escrito (CORRÊA, 2004). A Tabela 1 apresenta a frequência dos eixos tático e semântico. ${ }^{4}$

Tabela 1. Funcionamento dos MJ - aspectos tático-semânticos

\begin{tabular}{|c|c|c|c|c|c|}
\hline \multirow{2}{*}{ RELAÇÃO } & \multirow{2}{*}{ TOKEN } & \multirow{2}{*}{\multicolumn{2}{|c|}{ MJ }} & \multicolumn{2}{|l|}{ TYPE } \\
\hline & & & & \multirow{2}{*}{$\begin{array}{l}\mathbf{P} \\
87(100 \%)\end{array}$} & \multirow{2}{*}{$\begin{array}{l}\mathbf{H} \\
-\end{array}$} \\
\hline \multirow{4}{*}{ Causa (motivo) } & \multirow{4}{*}{$107(61,49 \%)$} & $\varnothing$ & $87(81,30 \%)$ & & \\
\hline & & $\mathrm{E}$ & $17(15,88 \%)$ & $17(100 \%)$ & - \\
\hline & & E também & $2(1,86 \%)$ & $2(100 \%)$ & - \\
\hline & & Porque & $1(0,93 \%)$ & $1(100 \%)$ & - \\
\hline Condição & $27(15,51 \%)$ & $\mathrm{Se}$ & $27(100 \%)$ & - & $27(100 \%)$ \\
\hline \multirow{2}{*}{ Adição } & \multirow{2}{*}{$15(8,62 \%)$} & $\varnothing$ & $9(60 \%)$ & $9(100 \%)$ & - \\
\hline & & $\mathrm{E}$ & $6(40 \%)$ & $6(100 \%)$ & - \\
\hline \multirow{2}{*}{ Fato-explicação } & \multirow{2}{*}{$7(4,02 \%)$} & $\varnothing$ & $6(85,71 \%)$ & $6(100 \%)$ & - \\
\hline & & Porque & $1(14,29 \%)$ & $1(100 \%)$ & - \\
\hline \multirow{4}{*}{ Tempo posterior } & \multirow{4}{*}{$6(3,44 \%)$} & Depois de & $3(50 \%)$ & - & $3(100 \%)$ \\
\hline & & Depois que & $1(16,66 \%)$ & - & $1(100 \%)$ \\
\hline & & E depois & $1(16,66 \%)$ & $1(100 \%)$ & - \\
\hline & & Depois & $1(16,66 \%)$ & - & $1(100 \%)$ \\
\hline Modo & $5(2,87 \%)$ & Ger & $5(100 \%)$ & - & $5(100 \%)$ \\
\hline \multirow{3}{*}{ Contraste } & \multirow{3}{*}{$4(2,29 \%)$} & Mas & $2(50 \%)$ & $2(100 \%)$ & - \\
\hline & & $\varnothing$ & $1(25 \%)$ & $1(100 \%)$ & - \\
\hline & & Senão & $1(25 \%)$ & - & $1(100 \%)$ \\
\hline Consequência & $2(1,14 \%)$ & $\varnothing$ & $2(100 \%)$ & - & $2(100 \%)$ \\
\hline Finalidade & $1(0,57 \%)$ & Para & $1(100 \%)$ & - & $1(100 \%)$ \\
\hline
\end{tabular}

Os textos revelaram encadeamentos com relações de sentido consideradas mais concretas - como adição e modo - e mais abstratas - como as causais (causa-motivo, fato-explicação, consequência), condicionais e contrastivas, além das marcadamente temporais e de uma ocorrência de finalidade. Destacam-se as 107 (61,49\%) ocorrências

\footnotetext{
${ }^{4}$ Em que token equivale à frequência total de cada relação de sentido e type, à de cada um dos MJ por meio dos quais essas relações são marcadas nos encadeamentos (cf. BYBEE, 2003).
} 
de causais, preferencialmente realizadas por meio da justaposição $(87-81,30 \%)$, mas também identificadas com os MJ e, e também e porque, em configurações exclusivamente paratáticas, cf. (5) e (6):

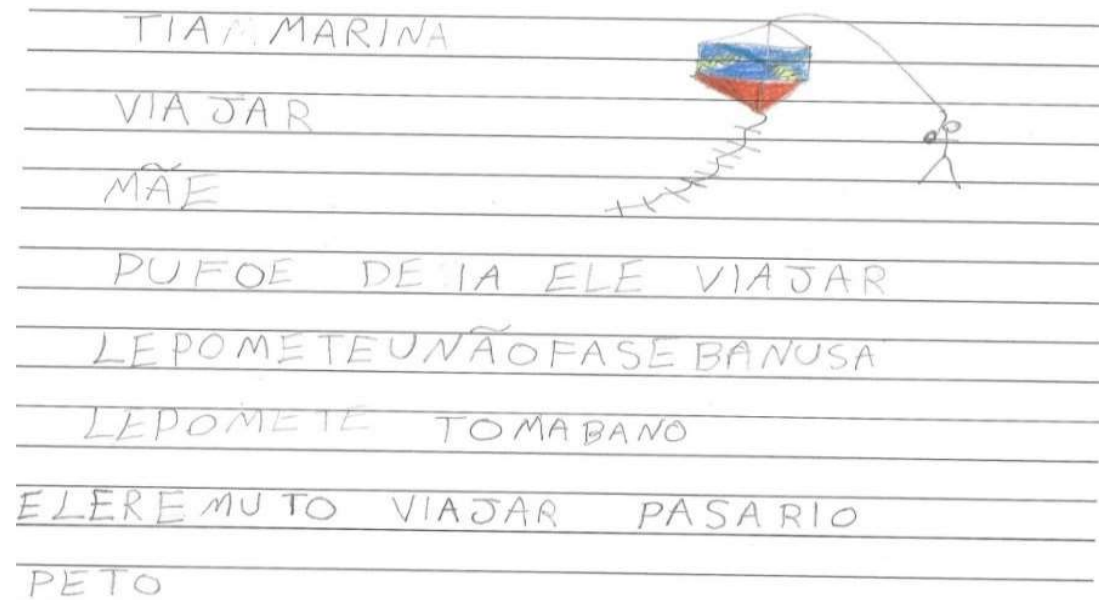

[P4/02]

(6)

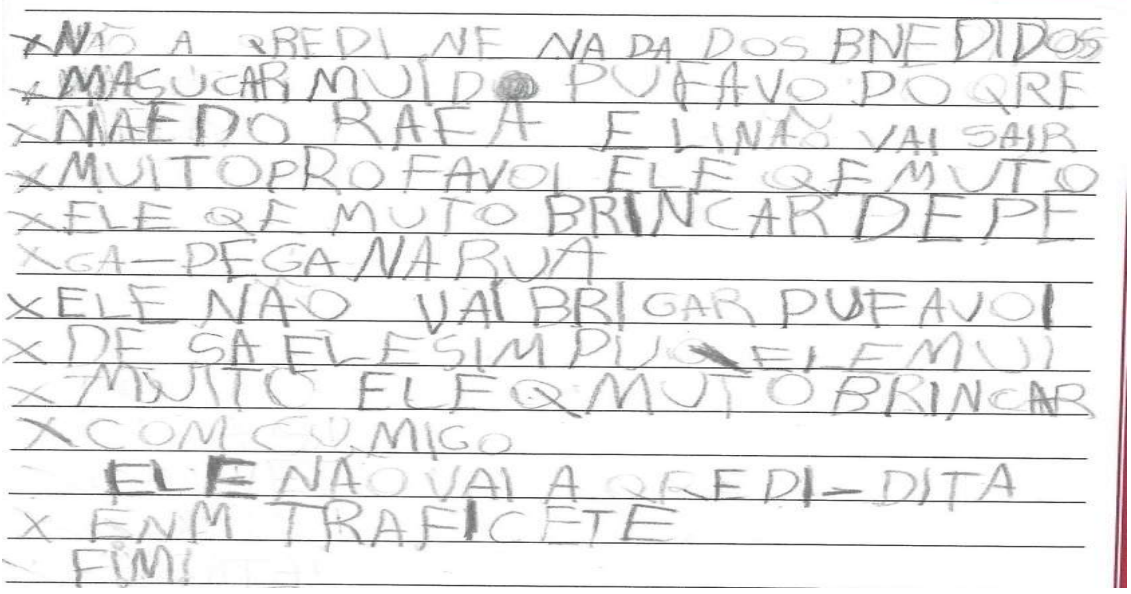

Em (5), o escrevente inicia seu texto com uma sequência de palavras, em formato de lista (tia Maria, viajar e mãe), que apresenta o universo semântico em que se dará o desenvolvimento do conteúdo apresentado na produção. Em seguida, expõe um pedido (Por favor, deixa ele viajar), em que há uma dependência do contexto, da proposta de produção do texto e dos itens que constam da lista apresentada anteriormente, marcada na necessidade de recuperação de informações não explicitadas no enunciado, como "Por favor, deixa ele [Rafa] viajar [para a casa da tia Marina]". A causa-motivação para o atendimento a esse pedido, caracterizado como $\mathrm{X}$, no encadeamento $X M J Y$, é apresentada em três enunciados, conectados de forma paratática, por meio da justaposição: "[porque] Ele prometeu não fazer bagunça, [porque] Ele promete tomar banho, [e porque] Ele quer muito viajar para Rio Preto.

A ocorrência de porque, no texto (6), representa um dado singular não apenas porque foi a única encontrada com essa acepção, mas também pelo seu funcionamento no encadeamento textual. O mecanismo insere um motivo, Porque, mãe do Rafa, ele não vai sair muito, para o atendimento a um pedido (deixar o Rafa brincar de pega-pega na rua), não explicitado no texto e que deve ser inferido a partir dos motivos elencados na tentativa de alcançar o "convencimento", como Ele quer muito, ele quer muito brincar de 
pega-pega na rua. O sujeito, portanto, estabelece um encadeamento do tipo (X) MJY, em que, embora com o uso do juntor prototípico da relação causal, o primeiro enunciado $X$ deve ser recuperado via contexto e co-texto. Esse tipo de funcionamento foi depreendido também com o uso da justaposição e de $e$, em 39 ocorrências (36,44\%), o que mostra a repetibilidade dessa estratégia de construção da TD argumentativa.

A acepção condicional foi constatada em 27 ocorrências (15,51\%), com o uso de se, em configurações hipotáticas, cf. exemplifica (7):

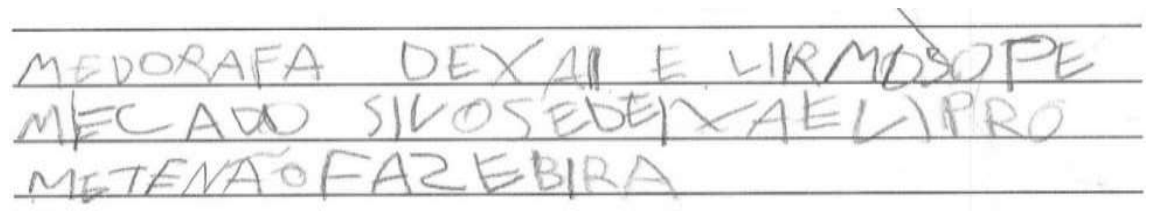

$[\mathrm{P5} / 24]$

Em (7), o encadeamento se $X, Y$ abre espaço para a argumentação, convocando enunciados que materializam um pedido, Mãe do Rafa, deixa ele ir no supermercado, e uma promessa, ele promete não fazer birra, condicionada a esse pedido se você deixar.

A adição foi constatada em 15 ocorrências paratáticas $(8,62 \%)$, cf. (8), com os usos de justaposição em 9 delas (60\%) e de $e$ em $6(40 \%)$ :

(8)

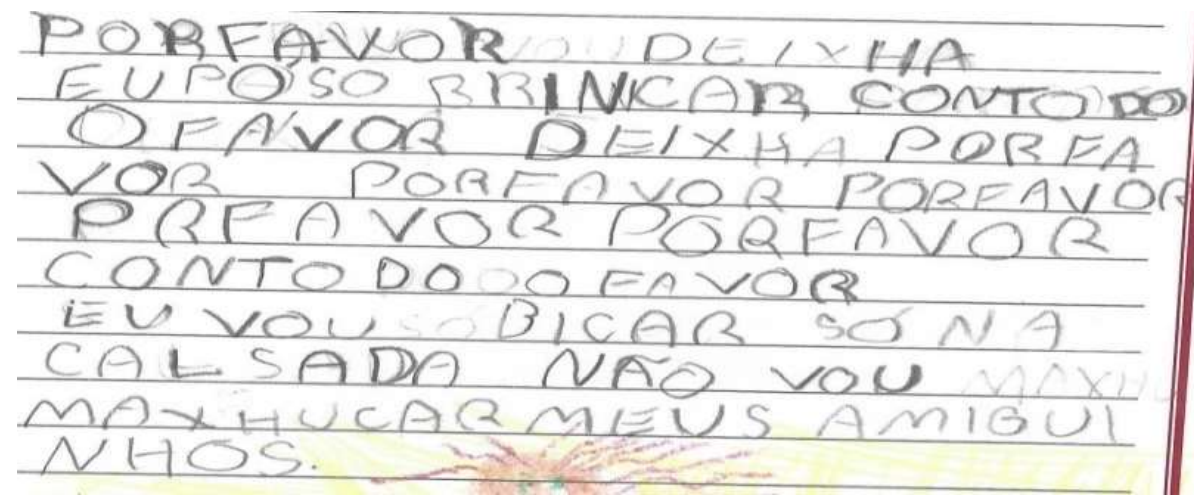

$[\mathbf{P 2} / 13]$

Em (8), uma ocorrência de justaposição marca a adição de uma informação nova, no texto, Por favor, deixa Ø eu posso brincar com todo o favor, e, na sequência, a repetição da mesma informação, deixa por favor, por favor [...]. Esse processo enfatiza o pedido e caracteriza uma estratégia discursiva empregada pelo sujeito no jogo que envolve o efeito de persuasão na tradição argumentativa.

A relação causal assume uma roupagem menos recorrente, em 7 (4,02\%) contextos, marcados pela apresentação de um fato, seguido de uma explicação, em encadeamentos justapostos (85,71\%), cf. (9), e com porque (14,29\%): 
(9)

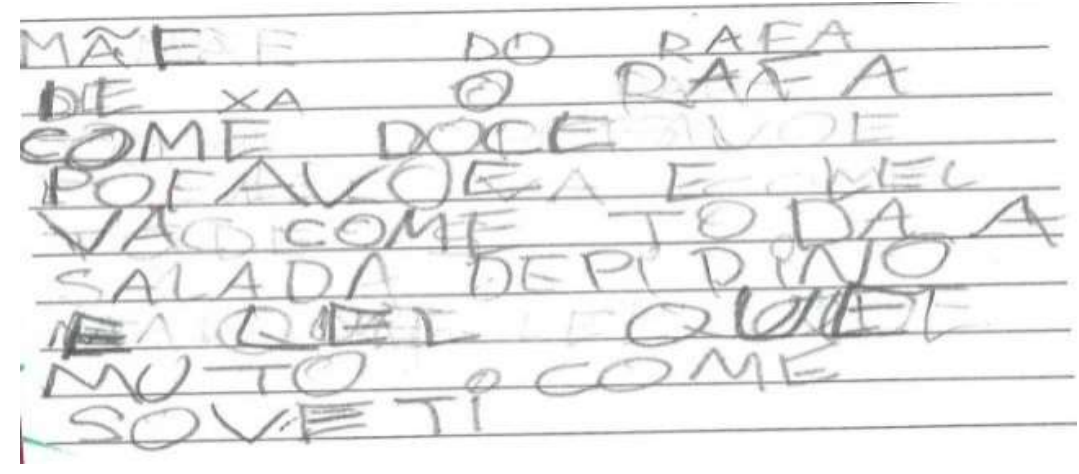

$[\mathbf{P 3} / 22]$

Em (9), o enunciado Ele quer muito comer sorvete ocorre como explicação para o fato apresentado no enunciado anterior. A ordem torna-se fixa, já que o adendo explicativo é inserido necessariamente após a apresentação de fatos que o fazem necessário no projeto de dizer dos sujeitos, dentro da configuração paratática $X M J Y$.

A noção semântica de tempo, exclusivamente, posterior, apresenta-se em 6 ocorrências (3,44\%), em que 50\% constitui-se com depois de (cf. (10)) e a outra metade varia entre depois que, e depois e depois. Com exceção da ocorrência de e depois, todas as demais são codificadas de modo hipotático:

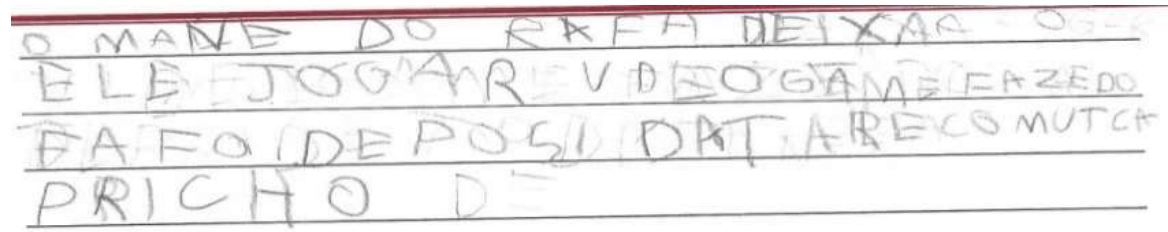

$[\mathbf{P 1 / 2 1 ]}$

Os encadeamentos com acepção de tempo posterior assumem funcionalidades diferentes na construção da argumentação. Em (10), o enunciado temporal depois da tarefa com muito capricho é a base da promessa, no "jogo argumentativo".

O uso do gerúndio foi constatado em cinco ocorrências hipotáticas $(2,87 \%)$ :

(11)

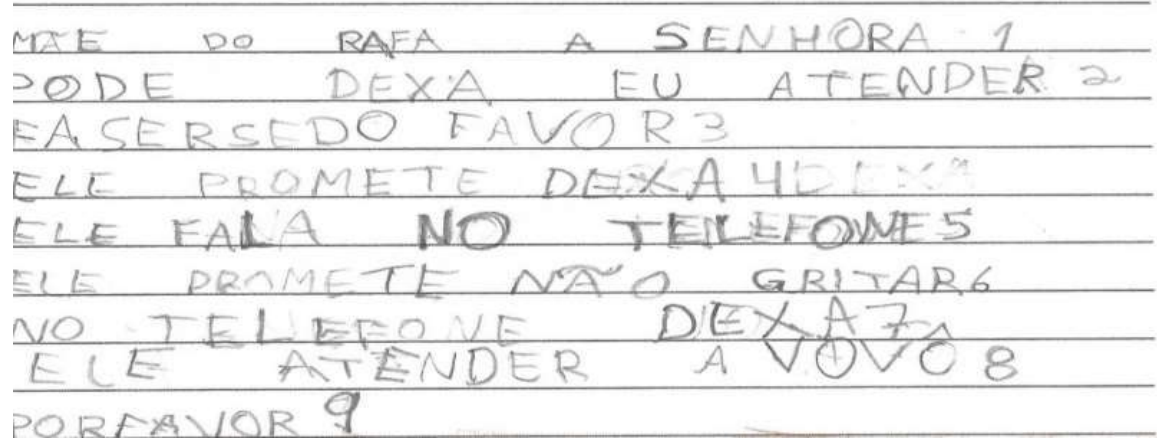

$[\mathbf{P 8} / 22]$

Em (11), fazendo favor, com acepção modal, atua na constituição da tradição de persuadir de acordo com a ilusão da argumentação, em que a polidez, enquanto traço fundamental dessa tradição e presente na grande maioria dos textos, assume papel importante no efeito de intencionalidade dos sujeitos. 
A noção de contraste foi constatada com baixa frequência $(4-2,29 \%)$, nos usos de mas $(2-50 \%)$, justaposição e senão ( $1-25 \%$ cada), como ilustra o texto (12):

(12)

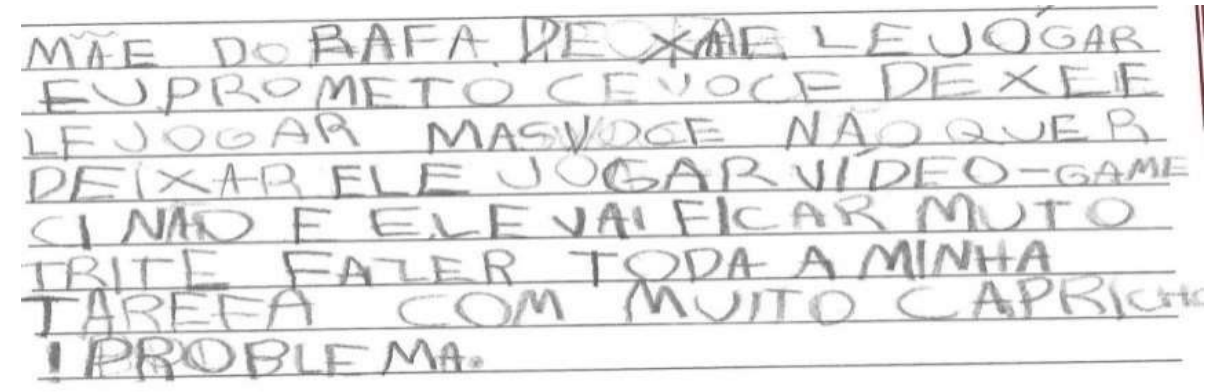

$[\mathbf{P 1} / 19]$

Em (12), o sujeito inicia seu texto com a apresentação do pedido: Mãe do Rafa, deixa ele jogar, e, em seguida, insere o motivo para o atendimento a seu pedido Eu prometo se você deixar ele jogar [...]. Esse enunciado, no entanto, é interrompido pela inserção de outros dois, que evidenciam a existência de um problema: mas você não quer deixar ele jogar vídeo-game e senão ele vai ficar muito triste. Além do contraste, marcado pelo uso de mas, em parataxe, e pela negativa que acompanha o uso de se, é possível justificar a leitura condicional presente no segundo enunciado (se você não deixar, ele vai ficar muito triste), fator decisivo para sua análise no nível hipotático. Após esses enunciados, o sujeito retoma aquele abandonado e o completa com (Eu prometo) [...] fazer toda a minha tarefa com muito capricho.

A noção de consequência, associada ao par causa-consequência, foi constatada em duas ocorrências (1,14\%), ambas marcadas pela justaposição. Por fim, a noção de finalidade mostrou-se em apenas uma ocorrência $(0,57 \%)$, com o uso de para:

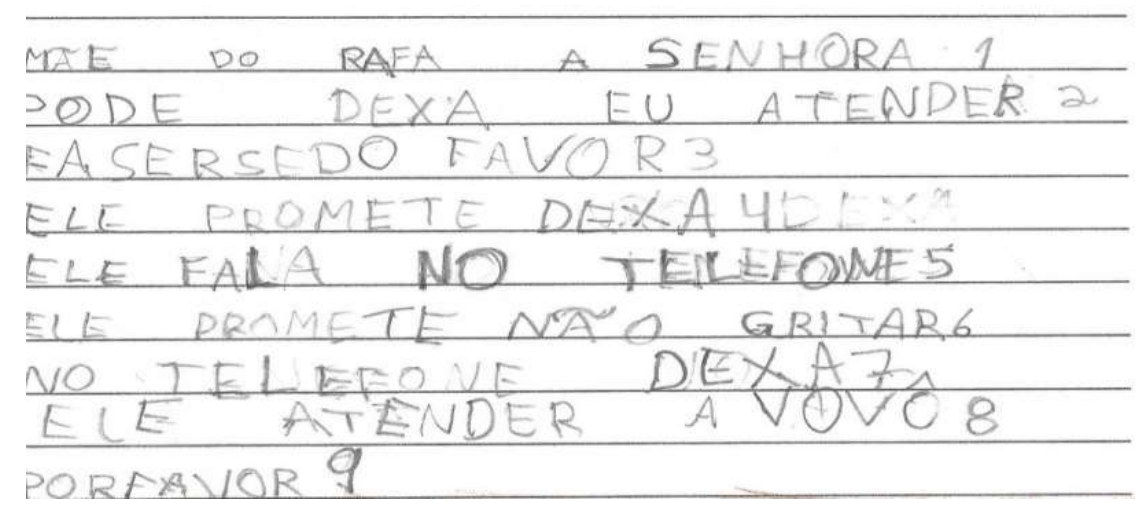

(14)

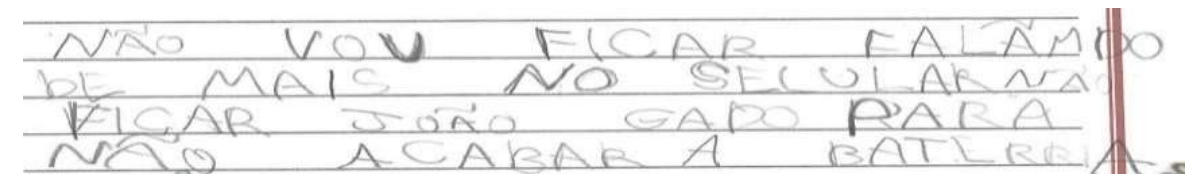

[P8/22]

$[\mathbf{P 8} / 15]$

Em (13), o sujeito inicia seu texto com a inserção de um pedido, Mãe do Rafa, a senhora pode deixar eu atender [o telefone] e lhe dá continuidade, inserindo causas/motivos para o atendimento ao seu pedido. Para finalizar seu texto, reforça o pedido, reinserindo-o, deixa ele atender a vovó, no encadeamento que abre espaço para sua interpretação como uma consequência das causas apresentadas anteriormente. Por sua vez, em (14), o sujeito não explicita o seu pedido, mas desenvolve o texto a partir da 
listagem de motivos que podem garantir a persuasão do outro. Na constituição do segundo enunciado que cumpre essa função, não ficar jogando para não acabar a bateria, marca a noção de finalidade prototipicamente.

A título de sistematização da descrição apresentada, segue o Gráfico 2:

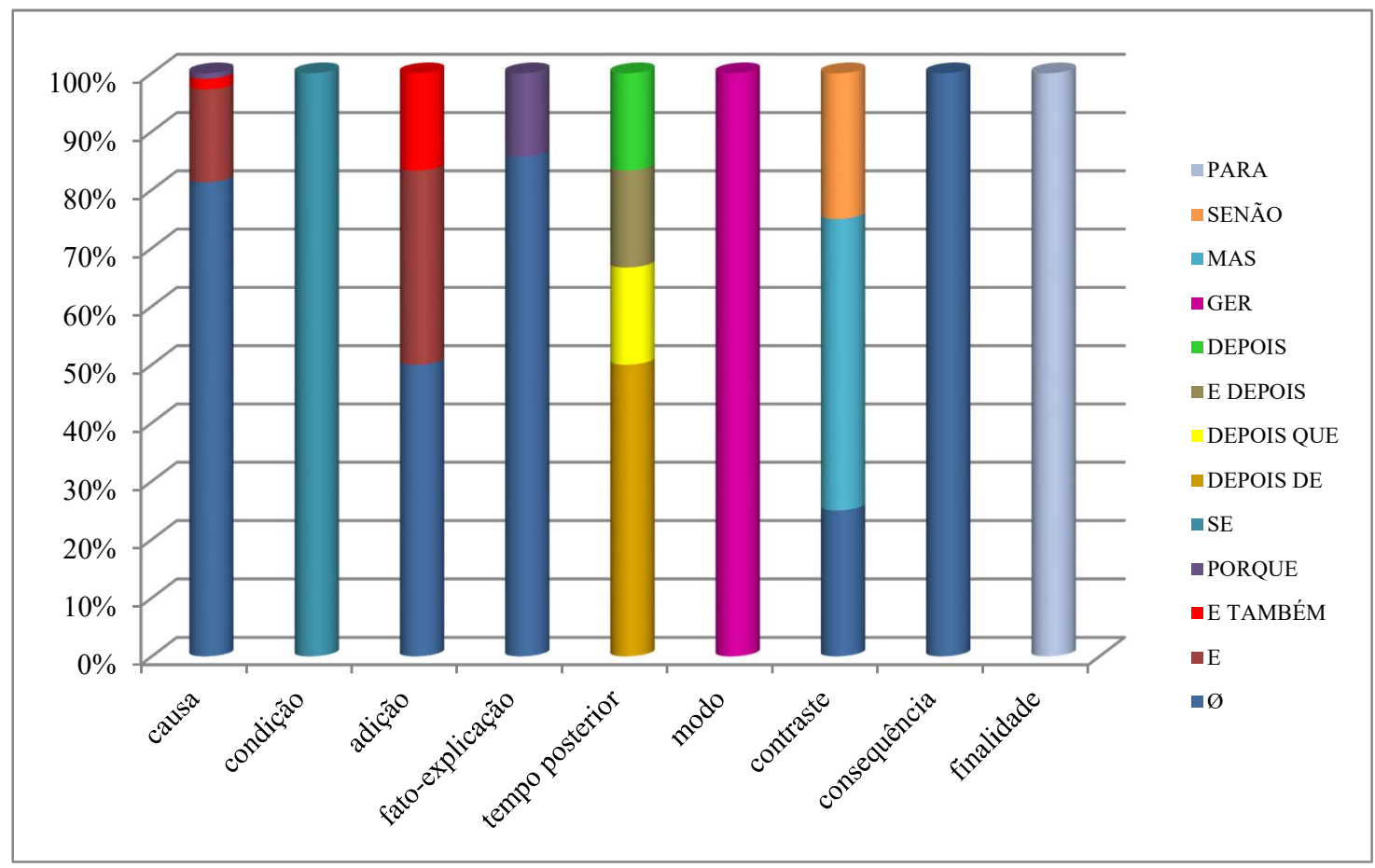

Gráfico 2. MJ em textos do primeiro ano do EF

Esse Gráfico apresenta os MJ empregados pelos escreventes na codificação dos diferentes efeitos de sentido interpretáveis a partir dos espaços abertos pelos encadeamentos do tipo $X M J Y$. Destaca-se que a noção mais recorrente nos dados é também a que apresenta maior diversidade de mecanismos atuantes (causa-justaposição, e, e também e porque). A segunda noção mais recorrente, a de condição, em contrapartida, codifica-se exclusivamente com se.

\section{Considerações finais}

Os resultados apresentados permitem duas considerações que, apesar de naturezas distintas, associam-se intimamente: (i) atestar a prototipicidade do MJ se no que tange ao sentido condicional e, consequentemente, sua circulação por práticas orais/letradas e faladas/escritas diversas, quando se trata dessa acepção; e (ii) atestar sua relação sintomática com a TD recorrente nos textos analisados, a argumentação. Nessa mesma direção, o emprego dos $\mathrm{MJ}$ - com destaque para os com acepção causal e condicional reflete a constituição de uma tradição de dizer/escrever caracterizada a partir da ilusão da argumentação, nos textos do universo investigado, conforme Campos (2005) e Pereira de Castro (1996). O efeito argumentativo é produzido, em meio à incompletude e à heterogeneidade que são constitutivas da linguagem/língua, e está intimamente ligado aos encadeamentos discursivos marcados na cadeia sintagmática, ainda que prioritariamente por zero. 
Nos textos investigados, a tradição argumentativa funciona na contenção da proliferação de sentidos, atribuindo aos enunciados encadeados, nos textos, os papéis de argumentos e conclusões que promovem um efeito de sentido, ainda que entre outros possíveis. Trata-se de uma de forma de enfocar os aspectos sintomáticos dos MJ, tomados em sua relação com a tradição, que os traduz como indícios da circulação dos sujeitos submetidos aos movimentos da própria língua e que, nesse processo, incorporam argumentos do outro, mantendo-se presos ao discurso do outro ou a outros discursos e fazendo crer/crendo que é possível argumentar com as palavras da língua.

\section{REFERÊNCIAS}

ABAURRE, M. B. M.; FIAD, R. S.; MAYRINK-SABINSON, M. L. T. Cenas de Aquisição de escrita: o sujeito e o trabalho com o texto. São Paulo: Mercado de Letras, 2002.

BYBEE, J. Mechanisms of Change Grammaticalization: the role of frequency. In: JOSEF, B.; JANDA, R. (Ed.). The Handbook of historical linguistics. Oxford, UK: Blackwell Publishing, 2003. p. 602-623.

CAMPOS, C. M. Efeitos argumentativos na escrita infantil ou a ilusão da argumentação. 2005. 218 f. Tese (Doutorado em Linguística) - Instituto de Estudos da Linguagem, Universidade Estadual de Campinas, Campinas, 2005.

CORRÊA, M. L. G. O modo heterogêneo de constituição da escrita. São Paulo: Martins Fontes, 2004.

CAPRISTANO, C. C. Mudanças na trajetória da criança em direção à palavra escrita. 2007. 253 f. Tese (Doutorado em Linguística) - Instituto de Estudos da Linguagem, Universidade de Campinas, Campinas, 2007.

COSERIU, E. O homem e sua linguagem. Rio de Janeiro: Presença, 1982.

Sincronia, diacronia e história: o problema da mudança linguística. Rio de Janeiro: Presença, 1979.

KABATEK, J. Tradiciones discursivas y cambio lingüístico. Lexis XXIX. 2, p. 151-177, 2005.

Tradiciones discursivas jurídicas y elaboración lingüística en la España medieval. Cahiers de Linguistique Hispanique Médiévale 27, p. 249-261, 2004.

$\mathrm{KOCH}, \mathrm{P}$. "Tradiciones discusivas y cambio lingüístico: el ejemplo del tratamiento vuestra merced en español". In: KABATEK, J. (Ed.). Sintaxis histórica del español y cambio lingüístico: nuevas perspectivas desde las Tradiciones Discursivas. Madrid, Iberoamericana, 2008.

KORTMANN, B. Adverbial Subordination: a typology and History of Adverbial Subordinators Based on European Languages. Berlin-New York: Mouton de Gruyter, 1997.

LONGHIN-THOMAZI, S. R. Aquisição de tradições discursivas: marcas de uma escrita heterogeneamente constituída. Alfa, São Paulo, 55 (1), p. 225-248, 2011. 
LOPES-DAMASIO, L. R. Junção em contexto de aquisição de escrita: uma abordagem das tradições discursivas. São Paulo: Estudos linguísticos, 43 (3), p. 1371-1386, 2014.

OESTERREICHER, W. Zur Fundierung von Diskurstraditionen. In: HAYE, T.; TOPHINKE, D. (Ed). Gattungen mittelalterlicher schriftlichkeit. Tübingen: Narr, 1997. p. $19-41$.

PEREIRA DE CASTRO, M. F. Aprendendo a Argumentar: um momento na construção da linguagem. 2. ed. rev. Campinas: Editora da UNICAMP, 1996 [1985].

RAIBLE, W. Linking clauses. In: HASPELMATH, M. et al. (Ed). Language typology and language universals: an international handbook. Berlin: Walter de Gruyter, 2001. p. 590-617.

TUÃO-BRITO, A. R. M. Junção e Tradições Discursivas: uma abordagem no domínio da aquisição de escrita. 2014. 159 f. Dissertação (Mestrado em Estudos da Linguagem) Instituto da Linguagem, Universidade Federal de Mato Grosso, Cuiabá, 2014.

ZAVAM, A. S. Por uma abordagem diacrônica dos gêneros do discurso à luz da concepção de tradição discursiva: um estudo com editoriais de jornal. 2009. $420 \mathrm{f}$. Tese (Doutorado em Linguística) - Centro de Humanidades, Universidade Federal do Ceará, Fortaleza, 2009.

Recebido em: 18/10/2016

Aprovado em: 29/11/2016 